\title{
Phenolics and antimicrobial activity of traditional stoned table olives 'alcaparra'
}

\author{
Anabela Sousa, ${ }^{\mathrm{a}}$ Isabel C. F. R. Ferreira, ${ }^{\mathrm{a}}$ Ricardo Calhelha, ${ }^{\mathrm{a}}$ Paula B. Andrade, ${ }^{\mathrm{b}}$ \\ Patrícia Valentão, ${ }^{\mathrm{b}}$ Rosa Seabra,${ }^{\mathrm{b}}$ Letícia Estevinho, ${ }^{\mathrm{a}}$ Albino Bento ${ }^{\mathrm{a}}$ and \\ José Alberto Pereira ${ }^{\mathrm{a}, *}$ \\ ${ }^{a}$ CIMO/Escola Superior Agrária, Instituto Politécnico de Bragança, Campus Sta Apolónia, \\ Apartado 1172, 5301-855 Bragança, Portugal \\ ${ }^{\mathrm{b}}$ REQUIMTE/Serviço de Farmacognosia, Faculdade de Farmácia da Universidade do Porto, \\ Rua Aníbal Cunha, 164, 4050-047 Porto, Portugal
}

Received 20 July 2006; revised 16 August 2006; accepted 22 August 2006

Available online 12 September 2006

\begin{abstract}
In the present work, we report the determination of phenolic compounds in 'alcaparra' table olives by reversed-phase HPLC/DAD, and the evaluation of their extract in vitro activity against several microorganisms that may be causal agents of human intestinal and respiratory tract infections, namely Gram positive (Bacillus cereus, Bacillus subtilis, and Staphylococcus aureus), Gram negative bacteria (Pseudomonas aeruginosa, Escherichia coli, and Klebsiella pneumoniae) and fungi (Candida albicans and Cryptococcus neoformans). Three flavonoidic compounds were identified and quantified: luteolin 7-O-glucoside, apigenin 7-O-glucoside, and luteolin. At low concentrations $(0.05 \mathrm{mg} / \mathrm{mL})$ 'alcaparra' extract revealed significant inhibition of both Gram positive and Gram negative bacteria growth, with exception of $P$. aeruginosa. Nevertheless, no antifungal activity was observed at the tested concentrations.

(C) 2006 Elsevier Ltd. All rights reserved.
\end{abstract}

\section{Introduction}

In the Mediterranean basin, olive oil, together with red wine, fruits, vegetables, and fish, are important constituents of the diet and are considered major factors in preserving a healthy and relatively disease-free population. In fact, epidemiological data show that the Mediterranean diet has significant protective effects against cancer and coronary heart disease. ${ }^{1,2}$ Olive products, typical components of the Mediterranean diet, contain high concentrations of complex phenols, which are endowed with strong antioxidant activity. ${ }^{3,4}$ The most important classes of phenolic compounds in olive products, namely table olives, include phenolic acids, phenolic alcohols, flavonoids, and secoiridoids. ${ }^{5-10}$

Many researches have demonstrated that the abovementioned biocompounds are able to inhibit or delay

\footnotetext{
Keywords: Luteolin; Luteolin 7-O glucoside; Apigenin 7- $O$ glucoside; 'Alcaparra'; Table olives; Antimicrobial activity.

* Corresponding author. Tel.: +351 273 303277; fax: +351 273 325405; e-mail: jpereira@ipb.pt
}

the rate of growth of a range of bacteria and microfungi, ${ }^{11}$ so that they might be used as alternative food additives or in integrated pest management programmes.

The increasing resistance to antibiotic represents the main factor justifying the need to find and/or develop new antimicrobial agents. Thus, some studies have focused on the antimicrobial agents and on the antimicrobial properties of plant-derived active principles (such as spices and essential oils), which have been used for a long time in traditional medicine to overcome infections. ${ }^{11}$ The use of crude extracts instead of isolated constituents may be more appropriate since a specific compound could be bioactive but the presence of other compounds present in the extracts could change its properties.

Recent studies on antimicrobial activity of olive products were developed, namely with olive leaves, ${ }^{12}$ olive fruits ${ }^{13}$ and their pure compounds, such as oleuropein $^{14,15}$ and hydroxytyrosol, ${ }^{14}$ and aliphatic aldehydes. ${ }^{16}$ Hydroxytyrosol and oleuropein have been shown to inhibit or delay the rate of growth of a range of bacteria and microfungi like Haemophilus influenza, Salmonella 
typhi, Vibrio parahaemolyticus and Staphylococcus aureus. ${ }^{14}$ Also, oleuropein inhibited the growth of Mycoplasma hominis, Mycoplasma fermentans, Mycoplasma pneumoniae and Mycoplasma pirum. ${ }^{15}$ Aldehydes, such as hexanal, nonanal, (E)-2-hexenal, (E)-2-heptenal, $(E)$-2-octenal and (E)-2-nonenal revealed antifungal activity against Trycophyton mentagrophytes, Microsporum canis and Candida spp. ${ }^{16}$

In the Northeast of Portugal, stoned halved olives (table olives), known as 'alcaparra', are largely produced and commercialized in the local market, constituting an important agro-economic factor for the local producers. This kind of table olives are processed from green or yellow-green healthy olive fruits, which are broken using a wood hammer, being the pulp and stone separated. The pulp is sliced into two approximately equal parts, perpendicularly to the major axis of the fruit, and placed in water, daily changed during a week to remove its bitterness. As far as we know, there are no reports on the nature and/or concentrations of phenolic compounds in 'alcaparra' olive and on its antimicrobial activity.

Therefore, in the present work, the phenolic compounds of this kind of Portuguese table olives were determined. A screening of 'alcaparra' extracts, antibacterial activities against Gram positive (Bacillus cereus, B. subtilis and Staphylococcus aureus) and Gram negative bacteria (Pseudomonas aeruginosa, Escherichia coli and Klebsiella pneumoniae) and of antifungal capacity (Candida albicans, Cryptococcus neoformans) was also performed.

\section{Results and discussion}

\subsection{Phenolic compounds in 'alcaparra' olives}

'Alcaparra' table olives presented a chemical profile composed of three identified phenolic compounds: luteolin 7-O-glucoside, apigenin 7-O-glucoside, and luteolin (Figs. 1 and 2). Three unidentified flavonoidic compounds (a, b, and c) and one hydroxycinnamic derivative were also detected in the methanolic extract (Fig. 2). The existence of several other compounds, namely hydroxytyrosol, tyrosol, 5- $O$-caffeoylquinic acid, verbascoside, cyanidin 3-O-glucoside, cyanidin 3-O-rutinoside, oleuropein, rutin, and quercetin 3-O-rhamnoside, described in olive fruits, ${ }^{8}$ was also checked, but it were not detected in the analysed sample. Other extraction solvents were used, namely hydromethanol and water, presenting all the extracts the same qualitative composition and similarities in the quantitative analysis. This happens, once traditional stoned table olives 'alcaparra' suffered a treatment which includes several washes with water, so the most polar compounds are not present in highest amounts in the analysed 'alcaparra' samples. So, the three mentioned solvents extract the phenolic compounds to the same extent. As expected, in all the extractions with the mentioned solvents, luteolin was the major phenolic compound (data not shown). As methanol comprised more compounds of several different polarities than the others, it was chosen for the quantification purposes, allowing a better comparison between the 'alcaparra' olives and other types of olives.

As far as we know, it is the first time that information about phenolic compounds in 'alcaparra' stoned table olives is reported. The quantification of the identified phenolics (Table 1) revealed that luteolin was the compound present in the highest amount, corresponding to ca. $91 \%$ of total amount of identified compounds, while apigenin 7-O-glucoside was the minor one (ca. $1 \%$ of total phenolics).

Several studies on phenolic composition of other different kinds of table olives, namely Spanish-style green olives in brine, naturally or turning colour table olives in brine, Kalamata olives in brine and oxidized table olives in brine were performed. ${ }^{7,17-20}$ These studies showed that the major phenolic compounds presented in table olives were tyrosol, hydroxytyrosol, and oleanolic acid and that their concentration depended on the degree of maturation and on the treatment method of olive drupe untill they become edible.<smiles>CC(O)C(O)C(O)C(O)Oc1cc(O)c2c(=O)cc(-c3ccc(O)c(O)c3)oc2c1</smiles>

1Luteolin 7-O-glucoside<smiles>CC1(CO)OC(Oc2cc(O)c3c(=O)cc(-c4ccc(O)cc4)oc3c2)C(O)C(O)C1O</smiles>

2 Apigenin7-O-glucoside<smiles>O=c1cc(-c2ccc(O)c(O)c2)oc2cc(O)cc(O)c12</smiles>

3 Luteolin

Figure 1. Flavonoid compounds identified in the 'alcaparra' sample. 


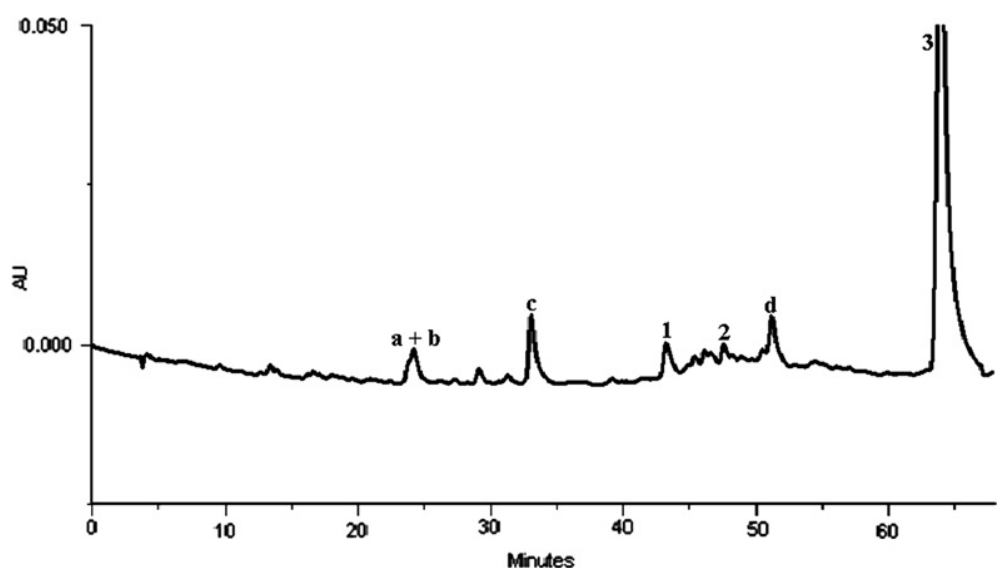

Figure 2. HPLC phenolic profile of 'alcaparra' table olives sample. Detection at $320 \mathrm{~nm}$. (1) Luteolin 7-O-glucoside; (2) apigenin 7-O-glucoside; (3) luteolin; (a), (b), (c) unidentified flavonoidic derivatives; (d) unidentified hydroxycinnamic acid derivative.

'Alcaparra' table olives show a singular phenolic profile that is most probably related with the technological process to which they are subjected. As mentioned above, the bitterness of 'alcaparra' is removed in the pulp washing, and this may justify the absence of secoiridoids like oleuropein. In addition, glycosidic phenolic compounds and other polar compounds presenting higher water solubility may also be extracted during this process, leading to its loss. So, due to its less polarity than other phenolics, the existence of a very high content of luteolin in 'alcaparra' table olives is not surprising.

\subsection{Antimicrobial assays}

The 'alcaparra' aqueous extract was screened for its antimicrobial activity against $B$. cereus, $B$. subtilis, $S$. aureus (Gram positive), E. coli, P. aeruginosa, K. pneumoniae (Gram negative) bacteria, and C. albicans and

Table 1. Phenolic compounds content in table olive 'alcaparra' sample $(\mathrm{mg} / \mathrm{kg} \text {, dry basis })^{\mathrm{a}}$

\begin{tabular}{llrl}
\hline & Compound & Mean & SD \\
\hline $\mathbf{1}$ & Luteolin 7- $O$-glucoside & 9.3 & 0.1 \\
$\mathbf{2}$ & Apigenin 7-O-glucoside & 1.4 & 0.0 \\
$\mathbf{3}$ & Luteolin & 111.7 & 2.5 \\
& $\sum$ & 122.4 & \\
\hline
\end{tabular}

$\overline{{ }^{a} \text { Results are expressed as means of three determinations. SD, standard }}$ deviation. $\sum$, sum of the identified phenolic compounds.
C. neoformans (fungi). Aside from concerns with food quality degradation, these microorganisms may be causal agents of intestinal infections in humans. The minimal inhibitory concentration (MIC) values for bacteria and fungi (Table 2) were determined as an evaluation of the antimicrobial activity of the tested 'alcaparra' sample.

The extract inhibited all the tested bacteria, with the exception of $P$. aeruginosa (Gram negative). B. cereus and $K$. pneumoniae were the most sensitive Gram positive and Gram negative bacteria, respectively (Table 2). However, the tested fungal species $C$. albicans and C. neoformans were resistant to 'alcaparra' extract.

As expected, the MICs of antibacterial (ampicillin) and antifungal (cycloheximide) control standards were lower than those for 'alcaparra' extract. Usually, pure active compounds reveal to have more activity than crude extracts.

Only the microorganisms that exhibited susceptibility in the screening performed in solid medium were submitted to assays in liquid medium, in order to determine their growth rates. The values obtained suggested a broad antimicrobial activity of 'alcaparra' extract in a concentration-dependent manner, against the tested bacterial strains. According to the percentage of inhibition of bacteria growth in the presence of different extract concentrations (Fig. 3) 'alcaparra' extract presented

Table 2. Antimicrobial activity of the 'alcaparra' extract

\begin{tabular}{lllllllll}
\hline Samples & \multicolumn{7}{c}{ MIC $(\mathrm{mg} / \mathrm{mL})$} \\
\cline { 2 - 9 } & B. cereus & B. subtilis & S. aureus & P. aeruginosa & E. coli & K. pneumoniae & C. albicans & C. neoformans \\
\hline Alcaparra & 25 & 25 & 25 & 50 & 50 & 10 & 50 & 50 \\
& $(++++)$ & $(++)$ & $(++)$ & $(-)$ & $(+++)$ & $(++)$ & $(-)$ & $(-)$ \\
Ampicillin & 0.00313 & 0.0125 & 0.00625 & 0.00625 & 0.00625 & 0.00625 & NT & NT \\
& $(++++)$ & $(++++)$ & $(++++)$ & $(++++)$ & $(++++)$ & $(++++)$ & 0.0125 & 0.00625 \\
Cycloheximide & $\mathrm{NT}$ & $\mathrm{NT}$ & $\mathrm{NT}$ & $\mathrm{NT}$ & $\mathrm{NT}$ & $\mathrm{NT}$ & $(++)$ & $(++++)$ \\
& & & & & & & $(++)$ \\
\hline
\end{tabular}

No antimicrobial activity $(-)$, inhibition zone $<1 \mathrm{~mm}$. Slight antimicrobial activity $(+)$, inhibition zone $2-3 \mathrm{~mm}$. Moderate antimicrobial activity $(++)$, inhibition zone $4-5 \mathrm{~mm}$. High antimicrobial activity $(+++)$, inhibition zone $6-9 \mathrm{~mm}$. Strong antimicrobial activity $(++++)$, inhibition zone $>9 \mathrm{~mm}$. Standard deviation $\pm 0.5 \mathrm{~mm}$. NT, not tested. 

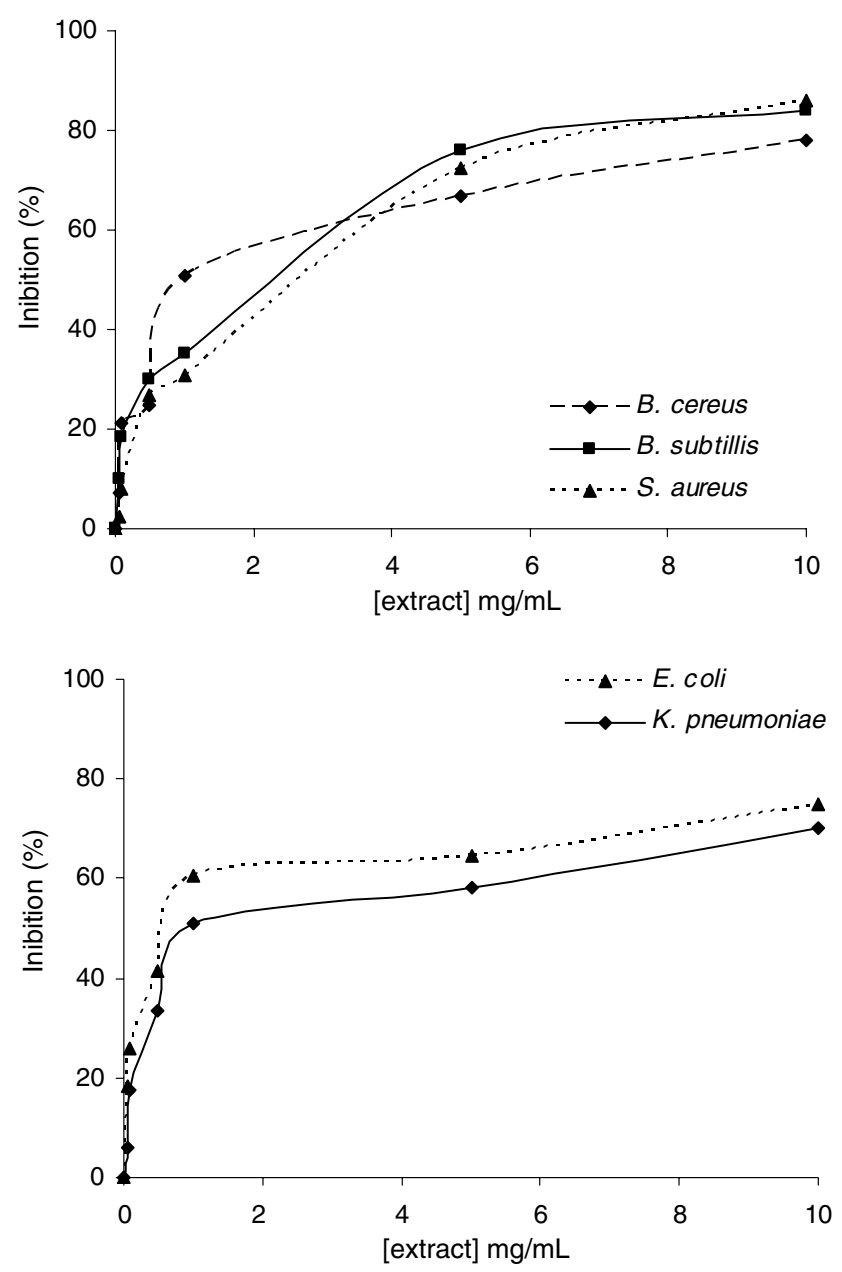

Figure 3. Inhibition (\%) of bacterial growth by different concentrations of 'alcaparra' extract.

antibacterial capacity in the order E. coli $>K$. pneumoniae $>B$. cereus $>B$. subtilis $>S$. aureus (Table 3). The extract at a concentration of $10 \mathrm{mg} / \mathrm{mL}$ decreased the absorbance values at $540 \mathrm{~nm}$ (Fig. 4), indicating inhibition of bacteria growth relatively to the control (without extract) during $24 \mathrm{~h}$ of incubation.

Certainly the chemical composition of 'alcaparra' extract conditioned the antibacterial effects observed. The high content of luteolin and the other phenolic compounds identified in the extract might contribute for its antimicrobial properties. In fact, the antimicrobial action of phenolics is well known and it is related to their ability to denature proteins, being generally classified as surface-active agents. ${ }^{21}$ They act by causing the leakage of cytoplasmic constituents such as protein, glutamate

Table 3. $\mathrm{IC}_{50}$ values of 'alcaparra' extract

\begin{tabular}{ll}
\hline Bacterial species & $\mathrm{IC}_{50}(\mathrm{mg} / \mathrm{mL})$ \\
\hline B. cereus & 0.981 \\
B. subtilis & 2.445 \\
S. aureus & 2.841 \\
E. coli & 0.722 \\
K. pneumoniae & 0.813 \\
\hline
\end{tabular}

or potassium and phosphate from bacteria, which may be due to disruption of cell peptidoglycan or damage of the cell membrane. The mode of action of phenolic compounds has been shown to be concentration dependent. ${ }^{11,15}$ In particular, luteolin has been described to possess antimicrobial activity against several bacterial species. $^{22-25}$

In conclusion, data obtained in this study demonstrate that 'alcaparra' table olives may be a good candidate for employment as antimicrobial agent against bacteria responsible for human gastrointestinal and respiratory tract infections. These results are particularly important against $S$. aureus, a microorganism extensively studied due to its ability to produce enterotoxins, and against E. coli, both exceptionally resistant to a number of phytochemicals. Thus, it seems that dietary intakes of 'alcaparra' may lower the risk of bacterial infections particularly in the intestinal tract, mainly due to the protective action provided by its phenolic compounds.

\section{Experimental}

\section{1. 'Alcaparra' sample}

'Alcaparra' traditional stoned olives were purchased at a local market in Northeast Portugal and frozen. The sample was then lyophilized, reduced to a fine powder (20 mesh) and stored in an exsiccator protected from light.

\subsection{Identification and quantification of phenolic compounds}

3.2.1. Standards. The standards used were from Sigma (St. Louis, MO, USA) or Extrasynthèse (Genay, France). Methanol and formic acid were obtained from Merck (Darmstadt, Germany). The water was treated in a Milli-Q water purification system (Millipore, Bedford, MA, USA) before use.

3.2.2. Extraction of phenolic compounds. The extraction was achieved as previously reported ${ }^{26}$ with some modification: each sample (ca. $1.5 \mathrm{~g}$ ) was thoroughly mixed with methanol until complete extraction of these compounds (negative reaction to $\mathrm{NaOH} 20 \%$ ). The methanolic extract was filtered, evaporated to dryness under reduced pressure $\left(40{ }^{\circ} \mathrm{C}\right)$ and redissolved in methanol $(2 \mathrm{~mL}$ ) of which $20 \mu \mathrm{L}$ was injected for HPLC analysis.

3.2.3. HPLC-DAD system for analysis of phenolic compounds. Chromatographic separation was carried out as reported previously, ${ }^{26}$ with an analytical HPLC unit (Gilson), using a Spherisorb ODS2 column $(250 \times 4.6 \mathrm{~mm}, \mathrm{RP}-18,5 \mu \mathrm{m}$ particle size, Merck, Darmstadt, Germany) with the solvent system water/ formic acid (19:1) (A) and methanol (B), starting with $5 \%$ methanol and installing a gradient to obtain $15 \%$ $\mathrm{B}$ at $3 \mathrm{~min}, 25 \% \mathrm{~B}$ at $13 \mathrm{~min}, 30 \% \mathrm{~B}$ at $25 \mathrm{~min}, 35 \% \mathrm{~B}$ at $35 \mathrm{~min}, 40 \% \mathrm{~B}$ at $39 \mathrm{~min}, 45 \% \mathrm{~B}$ at $42 \mathrm{~min}, 45 \% \mathrm{~B}$ at $45 \mathrm{~min}, 47 \% \mathrm{~B}$ at $50 \mathrm{~min}, 48 \% \mathrm{~B}$ at $60 \mathrm{~min}, 50 \% \mathrm{~B}$ at $64 \mathrm{~min}, 100 \% \mathrm{~B}$ at $66 \mathrm{~min}$, and $100 \% \mathrm{~B}$ at $68 \mathrm{~min}$. 

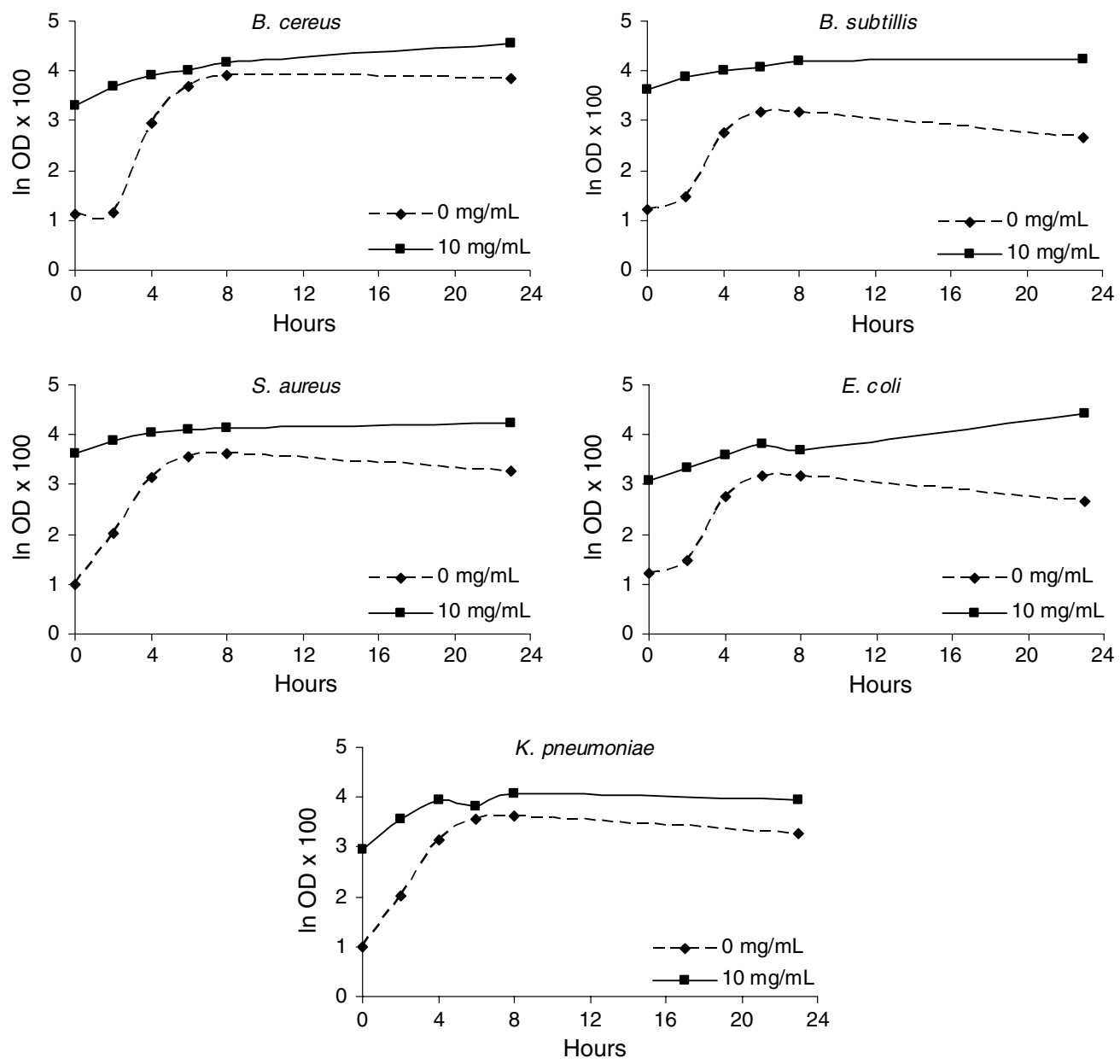

Figure 4. Bacterial growth in the presence of 'alcaparra' extract $(10 \mathrm{mg} / \mathrm{mL})$ and in the absence of extract $(0 \mathrm{mg} / \mathrm{mL})$ along the incubation period.

The flow rate was $0.9 \mathrm{~mL} / \mathrm{min}$. Detection was achieved with a diode array detector, and chromatograms were recorded at 280, 320, and $500 \mathrm{~nm}$. Spectral data from all peaks were accumulated in the range $200-600 \mathrm{~nm}$. The data were processed on a Unipoint ${ }^{\circledR}$ system software (Gilson Medical Electronics, Villiers le Bel, France). Peak purity was checked by software contrast facilities.

Phenolic compounds, quantification was achieved by the absorbance recorded in the chromatograms relative to external standards at $350 \mathrm{~nm}$.

\subsection{Antimicrobial activity}

3.3.1. Materials and reagents. Ampicillin and cycloheximide (analytical standard compounds) were of the highest available quality and purchased from Merck (Darmstadt, Germany). Water was treated in a Milli-Q water purification system (TGI Pure Water Systems, USA).

3.3.2. Extract preparation. Powdered sample $(5 \mathrm{~g})$ was extracted with $250 \mathrm{~mL}$ of boiling water for $45 \mathrm{~min}$ and filtered through Whatman No. 4 paper. The aqueous extract was frozen, lyophilized, and redissolved in water at a concentration of $50 \mathrm{mg} / \mathrm{mL}$, and analysed for their antimicrobial activity.
3.3.3. Microorganisms and culture conditions. The bacterial strains used were $B$. cereus CECT 148, B. subtilis CECT 498, S. aureus ESA 7, E. coli CECT 101, P. aeruginosa CECT 108 and $K$. pneumoniae ESA 8. The fungi strains used were C. albicans CECT 1394 and C. neoformans ESA 3. Microorganisms CECT were obtained from the Spanish-type culture collection (CECT) of Valencia University, while microorganisms ESA were clinically isolated strains identified in Microbiology Laboratory of Escola Superior Agrária de Bragança.

Microorganisms were cultured aerobically at $37^{\circ} \mathrm{C}$ in nutrient agar medium for bacteria and at $30^{\circ} \mathrm{C}$ (Scientific 222 oven model, 2003) in Sabouraud dextrose agar medium for fungi. Before experimental use, cultures from solid medium were subcultivated in liquid media, incubated and used as the source of inoculums for each experiment.

3.3.4. Preliminary assays for antimicrobial activity. A screening of antibacterial activities with three Gram negative ( $E$. coli, $P$. aeruginosa, and $K$. pneumoniae) and three Gram positive bacteria (B. subtilis, B. cereus, and $S$. aureus) was performed; antifungal activity (C. albicans, $C$. neoformans) was also assessed, and the minimal inhibitory concentrations (MICs in $\mathrm{mg} / \mathrm{mL}$ ) were determined by an adaptation of the agar streak dilution 
method based on radial diffusion. ${ }^{27,28}$ Suspensions of the microorganism were prepared to contain approximately $10^{8} \mathrm{cfu} / \mathrm{mL}$, and the plates containing agar medium were inoculated $(100 \mu \mathrm{L})$. A $50 \mu \mathrm{L}$ volume of each sample (2$50 \mathrm{mg} / \mathrm{mL}$ ) was pipetted into a hole (depth $3 \mathrm{~mm}$, diameter $4 \mathrm{~mm}$ ) made in the centre of the agar. Under the same conditions, different concentrated solutions of ampicillin (antibacterial) and cycloheximide (antifungal) were used as control standards. The assays with the standards were carried out using DMSO solutions because water could not dissolve the compounds. After toxicity assays this solvent showed to be not toxic (did not inhibited per si microorganisms growth).

The MIC was considered to be the lowest concentration of the tested sample to inhibit growth of bacteria or fungi on the plate, after $24 \mathrm{~h}$. The diameters of the inhibition zones corresponding to the MICs were measured in millimetres with an accuracy of $0.5 \mathrm{~mm}$ using a ruler. Each inhibition zone diameter was measured three times (three different plates) and the average was taken. A control using only inoculation was also carried out.

3.3.5. Test assays for antibacterial activity. A macrobroth-dilution technique was used to determine the growth inhibition of the susceptible bacteria (B. subtilis, B. cereus, S. aureus, E. coli and $K$. pneumoniae) to 'alcaparra' previously screened using the radial diffusion on agar. A nutrient medium ( $10 \mathrm{~g}$ tryptone, $5 \mathrm{~g}$ meat extract and water to $1 \mathrm{~L}$ ) was used to prepare the inocula after being sterilized in an autoclave (P Selecta model, 2002) at $121{ }^{\circ} \mathrm{C}$ for $\left.20 \mathrm{~min}\right)$. Erlenmeyer flasks $(50 \mathrm{~mL})$ with $10 \mathrm{~mL}$ of the liquid culture medium were inoculated with the bacteria suspension $\left(10^{8} \mathrm{cfu} / \mathrm{mL}\right)$ and each extract concentration to be tested $(0.05-10 \mathrm{mg} / \mathrm{mL})$ was added. Incubation was carried out for $24 \mathrm{~h}$ at $37^{\circ} \mathrm{C}$ in a rotary shaker (Stuart Scientific SI50 model, 2001) at $150 \mathrm{rpm}$. The growth of bacteria cultures was monitored by measuring optical density at $540 \mathrm{~nm}$ in a UV-visible spectrophotometer (Varian Cary 50 Scan model, 1998). Controls were carried out in the same conditions but in the absence of sample extract. All assays were carried out under aseptic conditions. Values for bacteria growth rate were obtained by linear regression analysis at the exponential growth range in the graphs of optical density at $540 \mathrm{~nm}$ versus incubation time. The equation curve slope was considered the rate of bacteria growth and was expressed relatively to the control $(100 \%)$. $\mathrm{IC}_{50}$ values (extract concentration which inhibits $50 \%$ of bacterial growth) were also determinate.

\section{References and notes}

1. Keys, A. Am. J. Clin. Nutr. 1995, 61, 1321S-1323S.

2. Trichopoulou, A.; Lagiou, P. Nutr. Rev. 1997, 55, 373389.
3. Baldioli, M.; Servili, M.; Perretti, G.; Montedoro, G. F. JAOCS 1996, 73, 1589-1593.

4. Litridou, M.; Linssen, J.; Schols, H.; Bergmans, M.; Posthumus, M.; Tsimidou, M.; Boskou, M. J. Sci. Food Agric. 1997, 74, 169-174.

5. Ryan, M.; Robards, K. Analyst 1998, 123, 31R-44R.

6. Soler-Rivas, C.; Espín, J. C.; Wichers, H. J. J. Sci. Food Agric. 2000, 80, 1013-1023.

7. Owen, R. W.; Haubner, R.; Mier, W.; Giacosa, A.; Hull, W. E.; Spiegelhalder, B.; Bartsch, H. Food Chem. Toxicol. 2003, 41, 703-717.

8. Vinhas, A. F.; Ferreres, F.; Silva, B. M.; Valentão, P.; Gonçalves, A.; Pereira, J. A.; Oliveira, M. B. P. P.; Seabra, R. M.; Andrade, P. B. Food Chem. 2005, 89, 561-568.

9. Brenes, M.; García, A.; García, P.; Rios, J. J.; Garrido, A. J. Agric. Food Chem. 1999, 47, 3535-3540.

10. Owen, R. W.; Mier, W.; Giacosa, A.; Hull, W. E.; Spiegelhalder, B.; Bartsch, H. Food Chem. Toxicol. 2000, 38, 647-659.

11. Cowan, M. C. Clin. Microbiol. Rev. 1999, 12, 564-582.

12. Markin, D.; Duek, L.; Berdicevsky, I. Mycose 2003, 46, 132-136.

13. Nychas, G. J. E.; Tassos, S. C.; Board, R. G. Lett. Appl. Microbiol. 1990, 13, 217-220.

14. Bisignano, G.; Tomaino, A.; Lo Cascio, R.; Crisafi, G.; Uccelle, N.; Saija, A. J. Pharm. Pharmacol. 1999, 51, 971974.

15. Furneri, P. M.; Marino, A.; Saija, A.; Uccella, N.; Bisignano, G. Int. J. Antimicrob. Agents 2002, 20, 293296.

16. Battinelli, L.; Daniele, C.; Cristiani, M.; Bisignano, G.; Saija, A.; Mazzanti, G. Phytomedicine 2006, 11, 558-563.

17. Marsilio, V.; Campestre, C.; Lanza, B. Food Chem. 2001, $74,55-60$.

18. Blekas, G.; Vassilakis, C.; Harizanis, C.; Tsimidou, M.; Boskou, D. G. J. Agric. Food Chem. 2002, 50, 3688-3692.

19. Romero, C.; Brenes, M.; Yousfi, K.; Garcia, P.; Garcia, A.; Garrido, A. J. Agric. Food Chem. 2004, $52,479-484$.

20. Boskou, G.; Salta, F. N.; Chrysostomou, S.; Mylona, A.; Chiou, A.; Andrikopoulos, N. K. Food Chem. 2006, 94, 558-564.

21. Denyer, S. P.; Stewart, G. S. A. B. Int. Biodet. Biodeg. 1998, 41, 261-268.

22. Basile, A.; Giordano, S.; López-Sáez, J. A.; Cobianchi, R. C. Phytochemistry 1999, 52, 1479-1482.

23. Sato, Y.; Suzaki, S.; Nishikawa, T.; Kihara, M.; Shibata, H.; Higuti, T. J. Ethnopharmacol. 2000, 72, 483-488.

24. Cottiglia, F.; Loy, G.; Garau, D.; Floris, C.; Casu, M.; Pompei, R.; Bonsignore, L. Phytomedicine 2001, 8, 302305.

25. Tshikalange, T. E.; Meyer, J. J. M.; Hussein, A. A. J. Ethnopharmacol. 2005, 96, 515-519.

26. Vinhas, A. F.; Silva, B. M.; Andrade, P. B.; Seabra, R. M.; Pereira, J. A.; Oliveira, M. B. P. P. J. Liq. Chrom. Relat. Tech. 2002, 25, 151-160.

27. Hawkey, P. M.; Lewis, D. A. Medical Bacteriology-A Practical Approach; Oxford University: UK, 1994, pp 181-194.

28. Ferreira, I. C. F. R.; Calhelha, R. C.; Estevinho, L. M.; Queiroz, M-J. R. P. Bioorg. Med. Chem. Lett. 2004, 14, 5831-5833. 